EXTENDED REPORT

\title{
Comparison of autologous serum eye drops with conventional therapy in a randomised controlled crossover trial for ocular surface disease
}

\author{
B A Noble, R S K Loh, S Maclennan, K Pesudovs, A Reynolds, L R Bridges, J Burr, O Stewart, \\ $S$ Quereshi
}

Br J Ophthalmol 2004;88:647-652. doi: 10.1136/bjo.2003.026211

\begin{abstract}
See end of article for authors' affiliations

.....................

Correspondence to: Mr B A Noble, Department of Ophthalmology, Clarendon Wing, The General Infirmary at Leeds, Belmont Grove, Leeds LS2 9NS; bruce@overblow. demon.co.uk
\end{abstract}

Accepted for publication 14 October 2003

\begin{abstract}
Aims: To evaluate the efficacy of $50 \%$ autologous serum drops against conventional treatment in ocular surface disorders refractory to normal treatments in a prospective randomised crossover trial. Method: Patients fulfilling ophthalmological and haematological entry criteria were randomised to either 3 months of autologous serum $50 \%$ followed by 3 months of their conventional treatment, or 3 months of conventional treatment, followed by 3 months of autologous serum. Clinical assessments, including Schirmer's test, rose Bengal, and fluorescein staining, were carried out on entry and at monthly intervals. Impression cytology was performed at entry, 3 and 6 months. Grading was carried out on degrees of squamous metaplasia and goblet cell density. Subjective comfort was recorded daily using the "faces" scale. These categorical scores were converted to linear measurement using Rasch analysis. Statistical analysis was carried out using Wilcoxon's signed rank test and ANOVA.

Results: 16 patients were recruited with 31 eyes studied. The ocular surface diseases chiefly included Sjögren's syndrome $(n=6)$ and keratoconjunctivitis sicca $(n=5)$. Impression cytology available in 25 of 31 eyes showed significant improvement on serum treatment, $p<0.02$. Rasch weighted faces scores were statistically significantly better with serum, $\mathrm{p}<0.01$.

Conclusion: The results of this randomised study provide further evidence of the beneficial effects of autologous serum in severe ocular surface disorders. For most of these patients, autologous serum was superior to conventional treatment for improving ocular surface health and subjective comfort.
\end{abstract}

$\mathrm{T}$ he majority of patients with dry eyes respond to conventional treatment aimed at optimising the ocular surface microenvironment. The ecosystem of the ocular surface depends on the dynamic interactions of healthy adnexae, adequate blink reflex, normal tear production, and ocular surface tissue, consisting of cornea and conjunctiva. Conventional therapeutic options include intensive tear supplements, punctal occlusion, contact lenses, and appropriate management of adnexal disease.

In spite of maximal conventional therapy there exists a cohort of patients who have persistent symptoms and signs. This represents a more serious ocular surface disorder with patients having significant visual impairment and disability. Autologous serum eye drops have been found in uncontrolled trials to be beneficial in these patients, improving the ocular surface and reducing symptoms. ${ }^{1-5}$ A recent controlled trial comparing autologous serum eye drops in one eye with the fellow eye as a control showed a non-statistically significant trend to improvement with serum drops. ${ }^{6}$ This effect has been attributed to various factors present in normal tears and serum. ${ }^{1-7}$

There are practical difficulties and theoretical risks in procuring autologous serum for patients with severe ocular surface disorders. Currently, autologous serum is prepared in an ad hoc manner, not conforming to the principles of good manufacturing practice regarding the collection and preparation of blood products. ${ }^{8}$

We have therefore sought to evaluate the efficacy of autologous serum for the treatment of severe ocular surface disorders using a prospective randomised controlled crossover study comparing 50\% autologous serum eye drops with conventional therapy. In addition we detail a manufacturing framework for the production of autologous serum eye drops which conforms to the principles of good manufacturing practice regarding the collection and preparation of blood products. ${ }^{8}$

\section{PATIENTS AND METHODS \\ Patient recruitment}

Ethics committee approval was granted for a prospective, randomised, crossover trial to compare the efficacy of autologous serum with conventional therapy in patients with severe ocular surface disease. Subjects for the study were identified from the cornea and external eye disease clinics at two teaching hospitals. Recruitment of potential subjects was also opened to other ophthalmologists and rheumatologists within north east England.

Potential patients were subject to an initial assessment to determine that the inclusion criteria, epitheliopathy with corneal/conjunctival rose bengal staining, Schirmer's test $<5 \mathrm{~mm}$, and punctal occlusion were fulfilled (table 1 ). Informed consent was obtained at point of inclusion by the primary investigators and the study carried out in accordance with the declaration of Helsinki. In order to participate, medical considerations required subjects to be fit enough to make a blood donation. ${ }^{9}$ Contraindications to donation are shown in table 2 .

\section{Clinical assessment}

Record was made of the underlying diagnosis, current and previous ocular therapies, systemic disease, and any systemic medication (table 3). Baseline assessment consisted of best corrected visual acuity and slit lamp examination with Rose bengal. The scoring system used for rose bengal staining of 


\section{Table 1 Inclusion criteria for the study}

Epitheliopathy on maximum conventional treatment with presence of corneal and conjunctival staining with rose bengal

Schirmer's test $<5 \mathrm{~mm}$

Upper and lower punctal occlusion

the ocular surface was as suggested by the National Eye Institute/Industry workshop on clinical trials for dry eyes. ${ }^{10}$ Schirmer's test without anaesthesia and tear film break up time was used to assess tear film stability and production. Fluorescein clearance test (FCT) was used to evaluate basal and reflex tear clearance. ${ }^{11}{ }^{12}$

Clinical assessments occurred at monthly intervals. These were carried out as at baseline except that Schirmer's test and tear film break up time were omitted. The ophthalmologists conducting the clinical testing did so without complete masking of the therapeutic status of the patients. Patients were asked to complete a subjective symptom scale, The faces scale, on a daily basis with the results of these were collected at each visit. ${ }^{13}$

\section{Treatment protocol}

Patients were randomised via assigned patient numbers and sealed regime envelopes by the hospital pharmaceutical research department to receive either 3 months of autologous serum $50 \%$ followed by 3 months of conventional treatment, or to start with 3 months of their conventional treatment, followed by 3 months of autologous serum. The conventional treatment consisted of continuing or restarting the current therapy already used by each individual patient (table 3 ). During the period of treatment with autologous serum, each patient was requested to use serum only. Patients were instructed to use one bottle of serum per day, instilling at the frequency of previous conventional therapy. Any remaining serum was discarded at the end of the day because no preservatives were used in the preparation. The patients were not masked to their treatments because of the difference in treatment containers and storage, glass bottles and freezer storage for serum treatment.

\section{Impression cytology}

Impression cytology was carried out over the inferotemporal limbus in both eyes using Millipore Millicell $12 \mathrm{~mm}$ plates. ${ }^{14}$ Impression cytology was performed at the baseline assessment, at 3 months following the first half of the trial treatment, and at 6 months following completion of therapy. The specimens obtained were transported in formalin. The Millipore plates were transferred to glass slides, stained with periodic acid Schiff (PAS) and cover slipped. A pathologist masked to the therapeutic status of the subject performed grading. Desquamation, goblet cell density, nucleocytoplasmic ratio, nuclear condensation and inflammatory cells were assessed and specimens assigned to a 3 point grading system: grade 0 (fully squamous epithelium), grade 1 (conjunctival type epithelium with partial goblet cell depletion) and grade 2 (normal conjunctival type epithelium) (fig 1).

\section{Blood collection and serum preparation}

A donation of blood was collected following the same procedure as for all allogenic blood donors, except that donation was made into a sterile blood pack without anticoagulant. Those patients who were not thought suitable to donate a full unit of blood had lesser amounts collected of between $250 \mathrm{ml}$ and $400 \mathrm{ml}$.
Table 2 Contraindications to donating blood for autologous use

Significant cerebrovascular or cardiovascular disease Anaemia (haemoglobin $<11 \mathrm{~g} / \mathrm{dl}$ )

Active bacterial infection

Positive for viral markers (HBV, HCV, HIV, syphilis)

Caution in patients on some antihypertensive medication-for example, $\beta$ blockers, ACE inhibitors

The donation was stored at $4^{\circ} \mathrm{C}$ for $2-3$ days to allow the blood to clot and the clot to retract fully. Serum was then separated from the clot of blood by centrifugation (a full donation yielding approximately $200 \mathrm{ml}$ of serum) following which an equivalent volume of sterile normal saline was then added to the serum. The process up to this point was carried out in a "closed pack" system by utilising a sterile connecting device. The diluted serum was then transferred to a laminar flow cabinet in a positive air pressure clean room where $3.0 \mathrm{ml}$ aliquots were dispensed into sterile screw capped glass bottles labelled with the patient's details and storage instructions. Five bottles from each batch were sampled
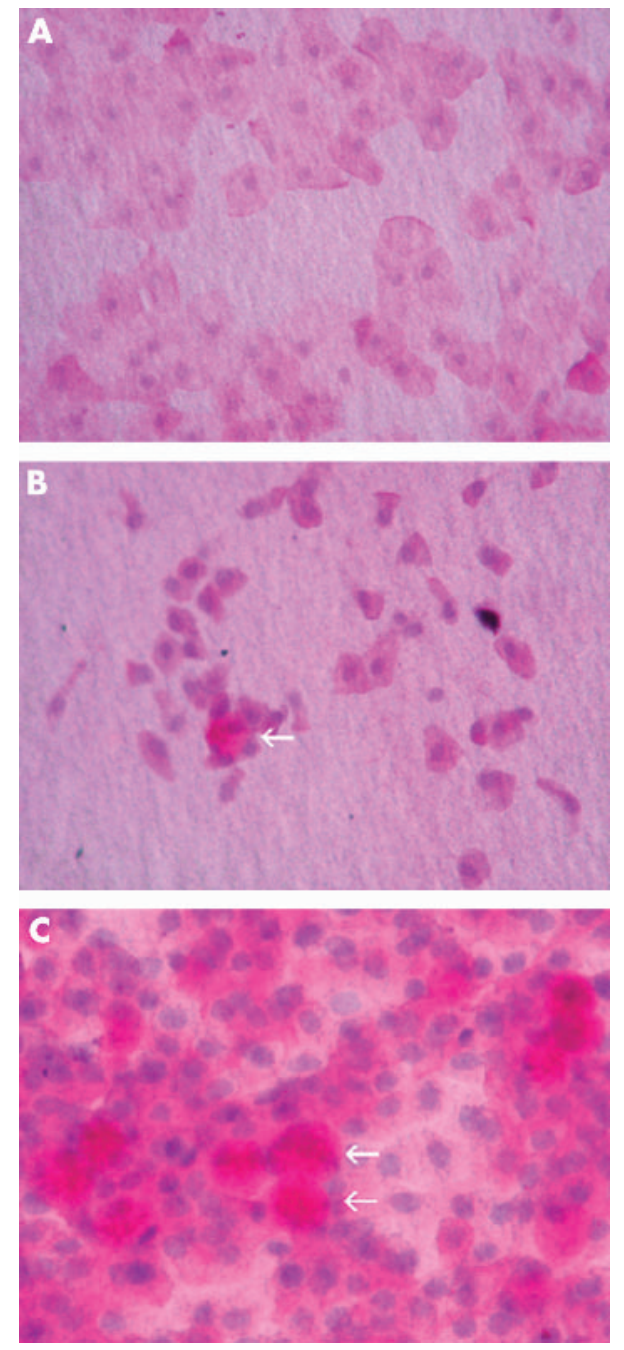

Figure 1 Photomicrographs showing the three point grading system for impression cytology: (A) grade 0 , fully squamous epithelium, (B) grade 1 , conjunctival type epithelium with partial goblet cell depletion, and (C) grade 2, normal conjunctival epithelium. The arrows in (B) and (C) point to goblet cells. Periodic acid Schiff (PAS) stained. Magnification $\times 3000$. 


\begin{tabular}{|c|c|c|c|c|}
\hline Patient & Sex & Age & Diagnosis & Conventional treatment at baseline \\
\hline 1 & M & 53 & \multirow{16}{*}{$\begin{array}{l}\text { Rosacea } \\
\text { Keratoconjunctivitis sicca } \\
\text { Graft versus host disease } \\
\text { Siögren's syndrome } \\
\text { Behchet's syndrome } \\
\text { Riley-Day syndrome } \\
\text { Dry eye } \\
\text { Siögren's syndrome } \\
\text { IgA ocular cicatrical } \\
\text { pemphigoid } \\
\text { Blepharitis + dry eye } \\
\text { Keratoconjunctivitis sicca } \\
\text { Sïggren's syndrome } \\
\text { Siögren's syndrome } \\
\text { Siögren's syndrome } \\
\text { Dry eye, congenital } \\
\text { glaucoma } \\
\text { Siögren's syndrome } \\
\text { Keratoconjunctivitis sicca }\end{array}$} & Liquifilm, Viscotears, Oc Lacrilube \\
\hline 2 & M & 61 & & Liquifilm, Oc Simple Eye \\
\hline 3 & M & 46 & & Liquifilm, Viscotears, llube \\
\hline 4 & $\mathrm{~F}$ & 71 & & Viscotears, Oc Simple Eye, Clobetasone Hypotears \\
\hline 5 & $\mathrm{~F}$ & 30 & & Viscotears, Chloramphenicol \\
\hline 6 & M & 59 & & Snotears, Oc Simple Eye \\
\hline 7 & $\mathrm{~F}$ & 37 & & Vital Eyes \\
\hline 8 & M & 58 & & $\begin{array}{l}\text { Lacrilube, Acetylcysteine, Retinoic acid, Hyaluronate } \\
\text { Predsol }\end{array}$ \\
\hline 9 & $\mathrm{~F}$ & 28 & & Doxycycline, Viscotears, Oc Betnesol \\
\hline 10 & M & 53 & & Liquifilm, Doxycycline, Fucthalmic, Oc Hydrocortisone \\
\hline 11 & $\mathrm{~F}$ & 41 & & Doxycycline, normal saline, Betnesol \\
\hline 12 & $\mathrm{~F}$ & 60 & & Hypromellose, Lacrilube, Hyaluronate \\
\hline 13 & $\mathrm{~F}$ & 67 & & Liquifilm, Lacrilube \\
\hline 14 & $\mathrm{~F}$ & 53 & & Viscotears, Betagan \\
\hline 15 & $\mathrm{~F}$ & 49 & & Hypromellose, Lacrilube \\
\hline 16 & M & 69 & & Healanoid, Liquifilm, Lacrilube, Salagen \\
\hline
\end{tabular}

and underwent bacterial culture before release. The bottles were recapped and transferred to a blast freezer where the diluted serum was quickly frozen to a temperature of $<-30^{\circ} \mathrm{C}$. The frozen serum was stored at this temperature until collection by the patients, still frozen, with dry ice in a sealed insulated cardboard box. One full donation produced approximately 130 bottles. Instructions were given to the patient about transferring the bottles to their home freezer.

\section{Data measurements and analysis}

Outcome measures consisted of subjective scores on the "faces" scale and objective scores from (i) ocular surface staining with rose bengal and (ii) grading of impression cytology specimens.

The faces scale is a single item, seven category rating scale where the subject is asked to grade their level of comfort (or pain) to match the appearance one of the seven faces, which vary in apparent effect (fig 2 ). ${ }^{13}$ The seven faces are assigned scores of 1 to 7 so the response intervals are assumed to be equidistant on a valid linear scale. The assumption that such an arbitrary scale represents a measure, although widespread, is not valid. ${ }^{15}$ However, statistical techniques such as Rasch analysis exist that allow the conversion of categorical data into valid linear measurement. This conversion should be considered an essential step before statistical manipulation of categorical data, and is gaining widespread use in ophthalmology for visual disability and quality of life outcomes assessment. ${ }^{16}{ }^{17}$ In this study, Rasch analysis was performed using Facets version 3.43 (www.winsteps.com/ minifac.htm) which calculates Wright and Masters' version of Rasch model estimates using joint maximum likelihood estimation. ${ }^{18} 19$ The Rasch model gives the probability of selecting a particular response category in terms of the interaction between "response severity" and subject measure (in this case, comfort) through an iterative logistic process. ${ }^{18}$ The resulting response scale calibrations and person measures are expressed in log odd units (natural logarithm of an odds ratio), or logits, positioned along a hierarchical scale with logits of greater magnitude representing increasing pain. These Rasch adjusted scores were analysed on a weekly basis, excluding the first week following each attendance, to establish median scores and compared across groups using ANOVA. Statistical analyses of impression cytology and rose bengal staining were carried out with the Wilcoxon signed ranked test.

\section{RESULTS}

A total of 32 patients were considered for the study. Six patients were excluded at initial assessment on medical criteria. Of these six medical exclusions, three had cardiovascular problems and three patients were on antihypertensive medication. Several patients had reduced donation volumes taken or donated isovolaemically. No patients suffered any adverse effects as a result of donation. Patients took a course of ferrous sulphate to minimise the risk of anaemia after donation, but one patient had to be excluded from making further donations because of a poor response to iron therapy. Of the remaining 26 patients, eight requested their withdrawal from the study after entry and two failed to attend. The main reasons for subjects requesting

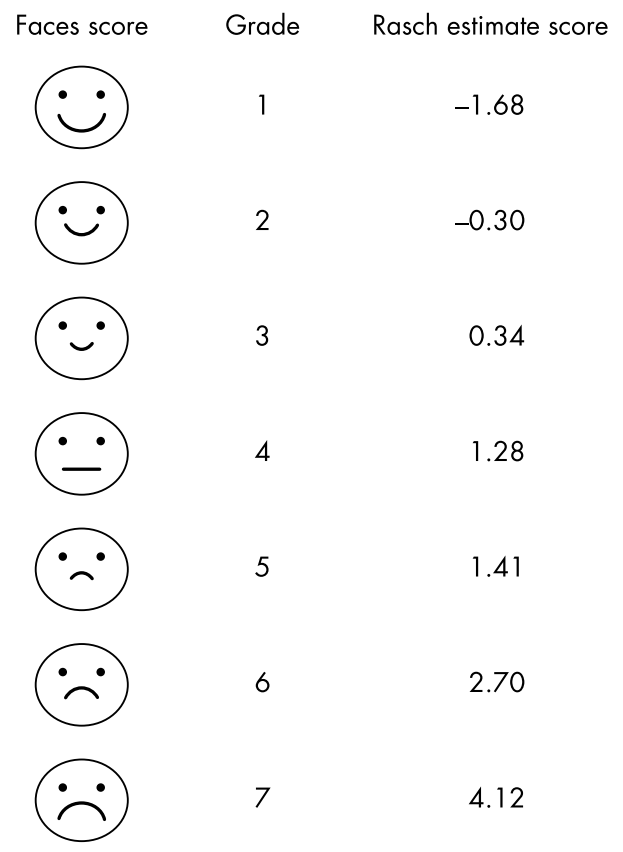

Figure 2 Subjective grading with description and Rasch estimates for the intervals on the faces score. This shows that the intervals are roughly 1 unit apart except that 4 and 5 are not different and 2 is half a unit better than 3 . These transformations are essential to make the scores linear. 
Table 4 Visual acuity

\begin{tabular}{|c|c|c|c|c|c|c|}
\hline Patient & Baseline RVA & Baseline LVA & Conv Rx RVA & Conv Rx LVA & Serum RVA & Serum LVA \\
\hline 1 & $6 / 5$ & $6 / 5$ & $6 / 5$ & $6 / 5$ & $6 / 5$ & $6 / 5$ \\
\hline 2 & $6 / 6$ & $6 / 6$ & $6 / 6$ & $6 / 6$ & $6 / 5$ & $6 / 6$ \\
\hline 3 & $6 / 6$ & $6 / 9$ & $6 / 9$ & $6 / 9$ & $6 / 6$ & $6 / 6$ \\
\hline 4 & $6 / 60$ & $6 / 18$ & $6 / 60$ & $6 / 18$ & $6 / 36$ & $6 / 24$ \\
\hline 5 & $\mathrm{PL}$ & $\mathrm{PL}$ & $\mathrm{PL}$ & $\mathrm{PL}$ & $\mathrm{PL}$ & $\mathrm{PL}$ \\
\hline 6 & $\mathrm{CF}$ & $6 / 5$ & $\mathrm{CF}$ & $6 / 6$ & $H M$ & $6 / 9$ \\
\hline 7 & $6 / 6$ & $6 / 9$ & $6 / 6$ & $6 / 12$ & $6 / 6$ & $6 / 9$ \\
\hline 8 & $6 / 60$ & $\mathrm{CF}$ & $C F$ & CF & $C F$ & $\mathrm{CF}$ \\
\hline 9 & $6 / 9$ & $6 / 9$ & $6 / 18$ & $6 / 6$ & $6 / 18$ & $6 / 5$ \\
\hline 10 & $6 / 12$ & $6 / 18$ & $6 / 6$ & $6 / 9$ & $6 / 18$ & $6 / 12$ \\
\hline 11 & CF & CF & CF & $\mathrm{CF}$ & $\mathrm{CF}$ & $\mathrm{CF}$ \\
\hline 12 & $6 / 6$ & $6 / 5$ & $6 / 9$ & $6 / 6$ & $6 / 5$ & $6 / 5$ \\
\hline 13 & $6 / 60$ & $\mathrm{CF}$ & $6 / 60$ & $\mathrm{CF}$ & $6 / 60$ & $\mathrm{CF}$ \\
\hline 14 & $\mathrm{AE}$ & $\mathrm{CF}$ & $\mathrm{AE}$ & $\mathrm{CF}$ & $\mathrm{AE}$ & $\mathrm{CF}$ \\
\hline 15 & $6 / 6$ & $6 / 6$ & $6 / 6$ & $6 / 6$ & $6 / 6$ & $6 / 6$ \\
\hline 16 & $6 / 60$ & $6 / 9$ & $6 / 60$ & $6 / 24$ & $6 / 60$ & $6 / 9$ \\
\hline
\end{tabular}

Figures in bold represent an improvement and those in italics a deterioration when compared to baseline in Snellen acuity.

Conv $\mathrm{Rx}=$ conventional treatment; Serum $\mathrm{Rx}=$ serum treatment; RVA = right visual acuity; $\mathrm{LVA}=$ left visual acuity; $\mathrm{PL}=$ perception of light; $\mathrm{HM}=$ hand movements at 1 metre; $C F=$ counting fingers at 1 metre; $A E=$ artificial eye.

withdrawal were either intolerance to rose bengal staining $(\mathrm{n}=4)$ or severe discomfort following impression cytology $(\mathrm{n}=3)$, all of these subjects requesting withdrawal at the second assessment - that is, month 1 of the trial period. Of the patients requesting withdrawal, three were started on autologous serum, one being intolerant to rose bengal staining and two complaining of discomfort following impression cytology. Another patient, randomised to conventional treatment first, developed a corneal abrasion following impression cytology at assessment on month 2 and withdrew from the trial. Two other patients failed to attend for assessment after entering the trial, one after obtaining autologous serum drops and the other after starting on conventional treatment. Since these 10 withdrawals happened to be allocated evenly to the two groups and all these patients withdrew at month 1 of the trial so that no data, subjective or objective, were available for study, and the 16 remaining patients were evenly allocated among groups, these withdrawals were not included in an intention to treat analysis.

Sixteen patients completed the trial with 31 eyes studied, one patient having an eviscerated fellow eye. The mean age was 54 years, range 30-71, and male:female ratio was 7:9. Randomisation assigned eight patients to start serum then conventional treatment with the reverse for the others.
Mean age for serum to conventional was 52 years, range 30-67, and conventional to serum 56 years, range 37-71. The majority, 11 of 16 patients, had keratoconjunctivitis sicca/Sjögren's syndrome, male:female ratio 4:7, with randomisation to initial treatment of serum in four and conventional in seven. The other patients had a variety of conditions (table 3).

During of the trial, one patient developed cataracts causing significant visual loss treated successfully by cataract extraction. There was otherwise no statistically significant change in acuity on either treatments at baseline, months 3 and 6 (table 4). FCT did not change from baseline on either treatments (baseline 5.25 (6.06), conventional 5.79 (SD 7.88), serum 4.71 (4.80), p>0.1 (table 5). Rose bengal staining scores did not change significantly (conventional mean 9.23 (4.1), serum mean 8.7 (4.0), p >0.05 (table 5).

Impression cytology (IC) analysis in 31 eyes confirmed a statistically significant difference between serum and conventional treatment $(\mathrm{p}<0.05$, Wilcoxon $)$ with IC being better on serum by inspection ( $\mathrm{n}=25,12$ improved, three deteriorated, 10 unchanged). Not all impression samples could be graded $(n=1)$ or taken bilaterally $(n=5)$ and no comparison therefore possible in six eyes (table 5). One patient had unilateral IC, the eviscerated eye not included.

Table 5 Table of impression cyłology, rose bengal, and fluorescein clearance scores

\begin{tabular}{|c|c|c|c|c|c|c|c|c|}
\hline Patient & $\begin{array}{l}\text { Conv Rx IC } \\
\text { grade R }\end{array}$ & $\begin{array}{l}\text { Conv Rx IC } \\
\text { grade L }\end{array}$ & $\begin{array}{l}\text { Serum IC } \\
\text { grade } R\end{array}$ & $\begin{array}{l}\text { Serum IC } \\
\text { grade L }\end{array}$ & Conv RB score & Serum RB score & Conv FCT & Serum FCT \\
\hline 1 & & 0 & 1 & 2 & 6 & 4 & 6 & 6 \\
\hline 2 & 2 & 1 & 2 & $\overline{1}$ & 15 & 14 & 3 & 3 \\
\hline 3 & & 0 & & 1 & 7.3 & 5.5 & 0 & 2 \\
\hline 4 & 1 & 1 & 1 & 0 & 16 & 16 & 0 & 3 \\
\hline 5 & 0 & 0 & 0 & 0 & 10 & 10 & 4 & 5 \\
\hline 6 & & 0 & & 1 & 7 & 5 & 2 & 2 \\
\hline 7 & 0 & 0 & 1 & 1 & 10.5 & 11.5 & 0 & 0 \\
\hline 8 & 0 & 0 & 2 & 2 & 15 & 8 & 0 & 0 \\
\hline 9 & & 1 & & 0 & 6 & 7 & 4 & 4 \\
\hline 10 & 0 & 0 & 0 & 0 & 12 & 13 & 12 & 12 \\
\hline 11 & & 0 & & 1 & 10 & 8 & 3 & 5 \\
\hline 12 & 0 & 0 & 1 & 1 & 12 & 8.3 & 4 & 9 \\
\hline 13 & 0 & 0 & 0 & 0 & 9 & 9 & 4 & \\
\hline 14 & & 2 & & 1 & 3 & 3.3 & 22 & 9 \\
\hline 15 & 0 & 0 & 1 & 1 & 6 & 4 & 16 & 0 \\
\hline 16 & & 1 & & 1 & 3 & 25 & 3 & 1 \\
\hline
\end{tabular}

For impression cytology, figures in bold represent an improvement and those in italics a deterioration with serum compared to conventional. Conv $\mathrm{Rx}=$ conventional treatment; Serum $\mathrm{Rx}=$ serum treatment; RVA = right visual acuity; $\mathrm{LVA}=$ left visual acuity; $\mathrm{PL}=$ perception of light; $\mathrm{HM}=$ hand movements at 1 metre; $C F=$ counting fingers at 1 metre; $A E=$ artificial eye. $I C=$ impression cytology; $R B=$ rose bengal; $F C T=$ fluorescein clearance test. 
Subjective scores were converted to Rasch estimates using the conversion values generated by Facets (fig 2) and the weekly medians for serum and conventionally treated groups compared using ANOVA. Patients were significantly better on serum treatment in both groups - that is, serum conventional and conventional serum (fig 3). In the serum conventional group (serum mean -0.61 (SD 1.19), conventional mean $0.90(1.05)) \mathrm{p}<0.01$, in the conventional serum group (serum mean 0.60 (1.06), conventional mean 1.45 (1.06)) $\mathrm{p}<0.01$. The subjective scores from conventional to serum showed a gradual improvement after the crossover-that is, after the ninth week. In contrast, when changing from serum to conventional treatment, there is a marked step deterioration after the ninth week (fig 4).

\section{DISCUSSION}

This study is the first reported randomised controlled clinical trial that confirms the beneficial effects of autologous serum in patients with severe ocular surface disease Although this is a small study, reflecting the stringent inclusion criteria, the improvements seen with autologous serum were statistically significant.

Six patients $(16 \%)$ were excluded during recruitment because of medical factors. A further eight patients (18\%) withdrew because of rose bengal intolerance or discomfort following impression cytology and two patients failed to attend assessments after receiving treatments. These withdrawals did not affect the balance of the randomisation to groups. This study was designed to examine the value of autologous serum on patients with severe ocular surface disease. Although "dry eye" patients (11/16) formed the majority of our cohort, we did not exclude other causes of severe ocular surface disease including five cases representing a heterogeneous group (Riley-Day, rosacea, ocular cicatricial pemphigoid, graft versus host disease, and congenital glaucoma). Inspection of the results in tables 4 and 5 suggest that this heterogeneous group performed similarly to the dry eye group.

The subjective measurements showed that 12 of 16 patients reported improvement in comfort and four patients showing no benefit. Impression cytology provided an objective measure that confirmed an improvement of the ocular surface, correlating well with the subjective scores. Twelve of 25 eyes showed improvement of the ocular surface as measured by impression cytology. Ten eyes showed no change with three demonstrating deterioration. While these two measures showed significant benefits for autologous

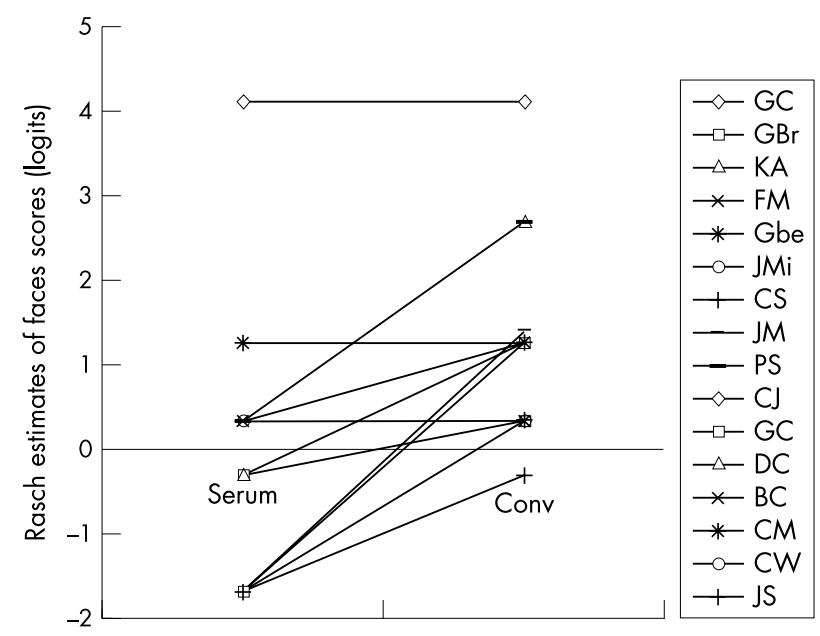

Figure 3 Median subjective Rasch scores demonstrating 12 of the patients had better scores on serum. serum, no differences were found for rose bengal staining, Schirmer's test, or fluorescein clearance test. These four nonsignificant clinical tests were conducted without complete masking of the observer. Conversely, a pathologist masked to the therapeutic status of the patients performed the grading of impression cytology and the subjective scoring of comfort was completed without the participation of any of the investigators. This suggests the potential sources of bias in the study were confined to non-significant outcomes. Therefore, bias does seem to jeopardise the conclusion that autologous serum is superior to conventional therapy.

Severe dry eye and ocular surface disease constitute a major management challenge. In this study, patients had significant ocular surface staining and symptomatology unresponsive to maximal conventional therapeutic modalities, including intensive preservative free tear supplements and punctal occlusion. The persistence of active ocular surface disease and symptoms with conventional treatments has been attributed to a combination of preservatives and increase susceptibility of corneal epithelium to toxicity in dry eye syndrome. ${ }^{20-22}$ The rationale underlying the proposed advantage of serum derivatives over conventional treatment was the presence of growth factors in tears, which were also found in serum. Fox et al initially reported the benefits of autologous serum in dry eyes from Sjögren's syndrome. ${ }^{1}$ This work has been further supported by the use of autologous serum in severe dry eyes by Tsubota et al. ${ }^{3}$ Recent in vitro work confirmed that pharmaceutical tear substitutes in contrast to serum do not maintain intracellular ATP levels and epithelial cell membrane integrity. ${ }^{4}$

The crossover design of the study confirms that these improvements are due to serum drops as the effect is reversed when treatment reverts to conventional therapy. This indirectly indicates that active components present in serum are required for the maintenance of a healthy ocular surface.

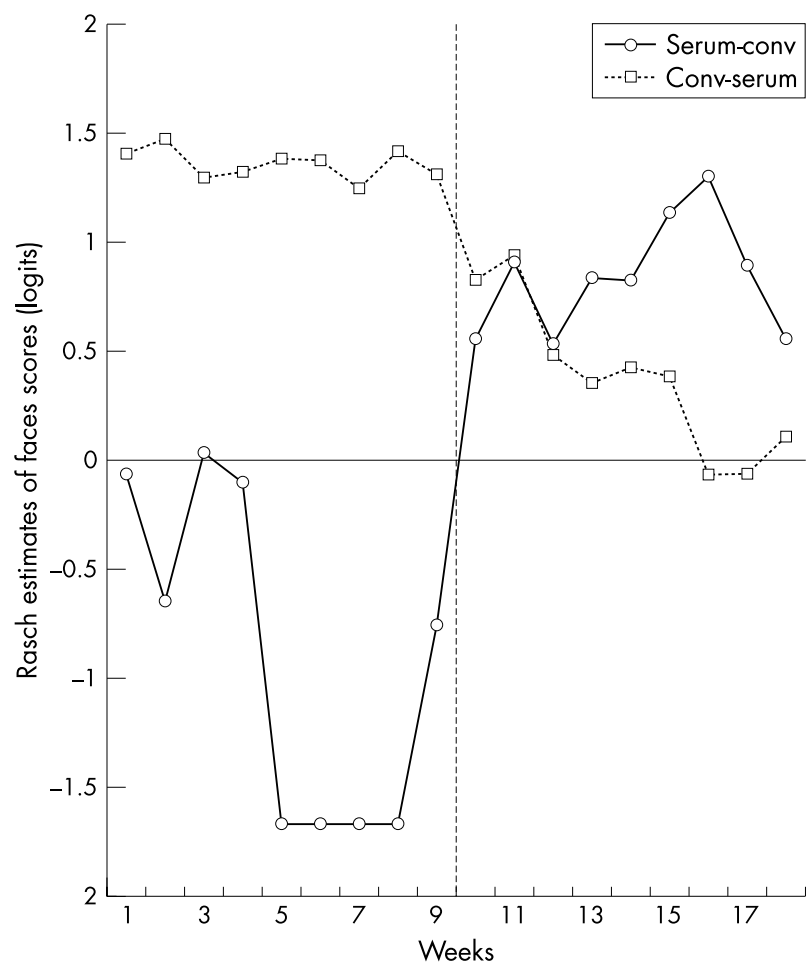

Figure 4 Weekly median Rasch estimate of "faces" scale scores. The broken line marks the point of crossover - that is, ninth to 10th week. The improvements from serum to conventional and deterioration from conventional to serum were statistically significant (ANOVA $p<0.01$ ). 
Several tear factors that have been identified to be of importance in the maintenance of normal corneal and conjunctival epithelium including epidermal growth factor (EGF), vitamin $A$, transforming growth factor $\beta$ (TGF- $\beta$ ), fibronectin, and other cytokines. ${ }^{323}{ }^{24}$. EGF, which is present in both basic and reflex tears, has been demonstrated to accelerate corneal epithelial proliferation. ${ }^{23}{ }^{24}$ Vitamin A when not present in tears in sufficient concentration may lead to epithelial metaplasia. ${ }^{3}$ TGF- $\beta$ is thought to control epithelial proliferation and maintain cells in an undifferentiated state. ${ }^{25}$ All these factors are also found in serum, albeit at different concentrations. In particular, TGF- $\beta$ and vitamin A are both found in far higher concentrations in serum, unlike EGF. ${ }^{3}$ The effects of such differences are unknown, though TGF- $\beta$ may have a detrimental effect to wound healing with its antiproliferative effects. In addition, serum also contains IgG, lysozyme, and complement which reduce the risk of contamination of samples and may reduce the risk of infection in an otherwise compromised ocular surface. ${ }^{3}$ While the components in serum responsible for its beneficial effect have not been identified, the possibility that the cause of any improvement is multifactorial must be considered. Moreover the ideal concentrations of the components of diluted serum have not been identified.

The lack of an agreed standard dilution of serum for use in anterior segment applications has led to concentrations from $20 \%$ to undiluted serum reported in studies for dry eye disease or persistent epithelial defects. ${ }^{13423}$ The preparation of serum drops may involve dilution with saline and the addition of antibiotics. ${ }^{13411}$ None of our patients had adverse reactions to serum treatment or developed secondary infections during the course of the study. As reported here, we have developed, with the help of the UK National Blood Service, a reliable and reproducible method for the production of autologous serum in accordance with the principles of good manufacturing practice. ${ }^{8}$

The major disadvantage of this treatment is the requirement for blood donation. This study shows that maintenance therapy and therefore repeated blood donation is required for continued benefit. The active components of serum are stable for up to 6 months when frozen ${ }^{323}$; therefore bleeding and serum preparation are required two to three times a year. Identifying the optimum dilution of serum and treatment regimen, in isolation or combination with conventional therapeutic measures, may well reduce the amount of blood required.

There has been no report to date on the effects and risks of prolonged application of autologous serum to the human ocular surface. There remains the possibility that serum contains active components that may adversely affect the ocular surface when applied in the wrong concentrations for prolonged periods. These issues should be the subjects of future investigations and the manufacturing process and study design described here provides an ideal starting point for such investigations.

\section{ACKNOWLEDGEMENTS}

This work has been supported by a grant from the National Blood Service. We thank Mr John Dart, FRCS, FRCOphth, for scrutinising the study protocol, Dr John McCarthy, FRCPath, for his advice on grading of impression cytology, Mr Peter Jackson for preparing the cytology specimens and Miss Wendy Parsons for her advice on the statistical analysis. We also thank Dr Angela Robinson, medical director National Blood Service, for her help and support. The
NHMRC Sir Neil Hamilton Fairley Fellowship 007161 supports Dr Konrad Pesudovs.

\section{Authors' affiliations}

B A Noble, R S K Loh, K Pesudovs, A Reynolds, J Burr, O Stewart, S Quereshi, Department of Ophthalmology, Clarendon Wing, The General Infirmary at Leeds, Belmont Grove, Leeds LS2 9NS, UK

S MacLennan, Leeds Blood Centre, National Blood Service, Bridle Path, Leeds LS15 7TW, UK

L R Bridges, Academic Department of Pathology, The General Infirmary at Leeds, Belmont Grove, Leeds LS2 9JT, UK

\section{REFERENCES}

1 Fox RI, Chan R, Michelson J, et al. Beneficial effects of artificial tears made with autologous serum in patients with keratoconjunctivitis sicca. Arthritis Rheum 1984:29:577-83.

2 Tsubota K, Higuchi A. Serum application for the treatment of ocular surface disorder. Int Ophthalmol Clin 2000;40:113-22.

3 Tsubota K, Goto E, Fujita H, et al. Treatment of dry eye by autologous serum application in Sjögren's syndrome. Br J Ophthalmol 1999;83:390-5.

4 Poon AC, Geerling G, Dart JKG, et al. Autologous serum eye drops for dry eyes and epithelial defects: clinical and in vitro toxicity studies. $\mathrm{BrJ}$ Ophthalmol 2001;85:1188-97.

5 Ogawa Y, Okamoto S, Mori T, et al. Autologous serum eye drops for the treatment of severe dry eye in patients with chronic graft-versus-host disease. Bone Marrow Transplant 2003;31:579-83.

6 Tananuvat N, Daniell M, Sullivan U, et al. Controlled study of the use of autologous serum in dry eye patients. Cornea 2001;20:802-6.

7 Tseng SCG, Tsubota K. Important concepts for treating ocular surface and tear disorders. Am J Ophthalmol 1997;124:825-5.

8 Great Britain Medicines Control Agency. Rules and guidance for pharmaceutical manufacturers and distributors 2002-incorporating EC guide to good manufacturing practice and good distribution practice-EC directives on manufacturing, wholesale distribution and good manufacturing practice. London: Stationery Office, 2002.

9 Voak D, Finney RD, Forman K, et al. Guidelines for autologous transfusion. I Pre-operative autologous donation, British Committee for Standards in Haematology Blood Transfusion Task Force. Transfusion Med 1993:3:307-16.

10 Lemp MA. Report of the National Eye Institute/Industry Workshop on Clinical Trials in Dry Eyes. CLAO J 1995;21:221-3.

11 Prabhasawat $P$, Tseng SCG. Frequent association of delayed tear clearance in ocular irritation. $\mathrm{Br} J$ Ophthalmol 1998;82:666-75.

12 Xu K-P, Yagi Y, Toda I, et al. Tear function index. A new measure of dry eye. Arch Ophthalmol 1995;113:84-8.

13 Chambers CT, Giesbrecht K, Craig KD, et al. A comparison of faces scales for the measurement of pediatric pain: children's and parents' ratings. Pain 1999;83:25-35.

14 Thiel MA, Bossart W, Bernaver W. Improved impression cytology techniques for the immunopathological diagnosis of superficial viral infections. Br J Ophthalmol 1997;81:984-8.

15 Massof RW, Fletcher DC. Evaluation of the NEl visual functioning questionnaire as an interval measure of visual ability in low vision. Vis Res $2001 ; 41: 397-413$

16 Stelmack JA, Stelmack TR, Massof RW. Measuring low-vision rehabilitation outcomes with the NEI VFQ-25. Invest Ophthalmol Vis Sci 2002:43:2859-68.

17 Pesudovs K, Garamendi E, Keeves JP, et al. The Activities of Daily Vision Scale (ADVS) for cataract surgery outcomes-re-evaluating validity with Rasch analysis. Invest Ophthalmol Vis Sci 2003;44:2892-9.

18 Wright BD, Masters GN. Rating scale analysis. Chicago: MESA Press, 1982

19 Linacre JM, Wright BD. Understanding Rasch Measurement: construction of Measures from Many-facet Data. J App Measurement 2002;3:486-512.

20 Gobbels M, Spitznas M. Corneal epithelial permeability of dry eyes before and after treatment with artificial tears. Ophthalmology 1992;99:873-8.

21 Burstein NL. The effects of topical drugs and preservatives on the tears and corneal epithelium in dry eye. Trans Ophthalmol Soc UK 1985; 104(Pt 4):402-9.

22 Wilson F. Adverse external ocular surface effects of topical ophthalmic medications. Surv Ophthalmol 1979;24:57-88.

23 Tsubota K, Goto E, Shimmura S, et al. Treatment of persistent epithelial defect by autologous serum application. Ophthalmology 1999;106:1984-9.

24 Ohashi Y, Motokura M, Kinoshita Y, et al. Presence of epidermal growth factor in human tears. Invest Ophthalmol Vis Sci 1986;27:1261-8.

25 Yoshino Y, Garg R, Monroy D, et al. Production and secretion of transforming growth factor beta (TGF- $\beta$ ) by the human lacrimal gland. Curr Eye Res 1996; 15:615-24.

26 Wilson SE, Lloyd SA, Kennedy RH. Basic fibroblast growth factor (FGFb) and epidermal growth factor (EGF) receptor messenger RNA production in human lacrimal gland. Invest Ophthalmol Vis Sci 1991;32:2816-20. 